\title{
"LA DESDICHA POR LA HONRA": GÉNESIS Y SENTIDO DE UNA NOVELA DE LOPE
}

La investigación de las fuentes es pedanteria despreciable cuando no sirve para esclarecer algo del misterio de la creación literaria. Felizmente, ya va perdiendo su prestigio la erudición muerta, que, en el caso de una comedia o una novela, amontonaba referencias a obras de igual o análogo asunto, y comparaba situaciones paralelas sin averiguar siquiera qué materiales manejó efectivamente el escritor. Por lo visto, lo que importaba en tales pesquisas era determinar los elementos no originales de la obra, y sacar por sustracción el resto atribuible a originalidad creadora. ¡Lástima de originalidad!

Ya sabemos que la creación literaria trabaja pocas veces sobre la pura experiencia vital del creador, triturada o no por su imaginación. Encontramos normal la utilización de materiales anteriormente elaborados por otros escritores; no menos normal la obediencia del poeta a unos determinados moldes o temas consagrados por el éxito. Hasta nos parece que la elección de la materia prima no es menos reveladora de la peculiaridad genial de un novelista $O$ dramaturgo que la guirnalda de situaciones imaginada por él para dar vida a dicha materia. $Y$, desde luego, la misma elección puede ser muy típica del ideal dramático o novelesco de un pueblo entero. Nos interesa enormemente entender los motivos, personales y colectivos, que hacen cuajar el núcleo inicial de una obra, aunque sabemos perfectamente que en este núcleo no se encierra, ni mucho menos, toda la originalidad de la creación. Tan creador es el acto de escribir, el ritmo de la ejecución-lenta o apresurada-, como la concepción del conjunto. Y probablemente más. . .

Así y todo, es de extrañar que la critica moderna, en su afán de analizar la creación de Lope, no se haya aprovechado más de la comodidad que ofrece el conocimiento de los materiales que él manejó, ya que están, en muchos casos, al alcance de nuestra mano. Aqui está, por ejemplo, la Crónica de las tres Ordenes de Rades y Andrada, utilizada por Lope en Fuente Ovejuna. Es evidente que el poeta sacó de allí no sólo la acción principal de su comedia - la rebelión del pueblo contra la tiranía del Comendador-, sino también la acción secundaria, o sea la toma de Ciudad Real por el Maestre y su reconquista por las tropas leales a Isabel y Fernando. ${ }^{1}$ Lope se apodera de estos elementos

1 Cf. Menéndez y Pelayo (Prólogo al vol. x de las Obras de Lope de Vega publicadas por la Academia Española, Madrid, 1899, pág. CLIX, o tomo v de los Estudios sobre el teatro de Lope de Vega, Madrid, 1925). Don Marcelino sólo se fija en la acción principal. 
en virtud de afinidades en parte misteriosas, pero también en virtud de las exigencias propias del espectáculo nacional: exigencias de un determinado esquema dramático, de un determinado ritmo de acción, de un determinado sentido de los personajes, de una determinada mescolanża de poesía sentimental y épica, poesía pastoril y romancero. Al idear una comedia más, se impone a él la comedia lopesca, ya cuajada en veinte años de experiencias anteriores, resultante de la actuación de unas compañías formadas por y para la representación de sus obras. Sólo teniendo en cuenta estos antecedentes entenderemos el valor de la materia prima descubierta por Lope en Radcs y Andrada. Pero, recíprocamente, el coiejo de la Crónica con la comedia nos sirve para penetrar algo en la intimidad de la creación lopesca y de su estilo propio. Creación improvisada, no por eso menos certera.

Así grandes pintores

manchan la tabla aprisa

exclamaba Lope con orguilo. ${ }^{2}$ Creación de alto interés para nuestra épo:a peliculera, hambrienta de csnectáculos que se guisan con los materiales más diversos en que lo visual y lo sonoro cuenta mucho más que la dialéctica de las ideas y de los sentimientos.

Entre las Novelas de Lope, hay una que sobresale por el desenfado con que está escrita, conforme a la teoría del género que encontramos expuesta en su proemio:

En este género de escritura ha de haber una oficina de cuanto se viniere a la pluma sin disgusto de los oídos, aunque lo sea de los preceptos, porque ya de cosas altas, ya de humildes, ya de episodios y paréntesis, ya de historias de fábulas, ya de reprehensiones y ejemplos, ya de versos y lugares de autores, pienso valerme para que ni sea tan grave el estilo que canse a los que no saben, ni tan desnudo de algún arte que le rcmitan al polvo los que entienden. Demás que yo he pensado que tienen las novelas los mismos preceptos que las comedias, cuyo fin es haber chado su autor contento y gusto al pueblo, aunque se ahorque el arte. ${ }^{3}$

A este arte nuevo de escribir novelas se amolda con singular garbo La desdicha por la honra, que se parece a una comedia por el fácil artificio de su maraña. Desesperado el galán Felisardo, que se creía de limpia nobleza española, al descubrir que sus padres están comprendidos en el bando de expulsión de los moriscos, pasa de la Corte del Virrey de Sicilia a la de Constantinopla, doncle sus aventuras sentimentales se entretejen con las sangrientas intrigas de la monarquía del gran turco, hasta que muere heroicamente al raptar a una sultana de origen andaluz, cuya vuelta a España, de no malograrse, había cie significar un triunfo de la $\mathrm{fe}$... Preterio la historia toda para digresiones

2 Égloga a Claudio (Bibl. Aut. Esp., vol. xxxvil, pág. 432).

3 La desdicha por la honra, en La Circe, con otras rimas y prosas, Madrid, 1624 , $f^{\circ} 109 \mathrm{v}^{\circ}$. Manejamos el facsímil de la Colección Tesoro (Madrid, 1935). 
sobre Constantinopla y la corte del gran Turco, para dichos agudos y pedanterías, para paréntesis o intercolunios, que en sus despropósitos llegan alguna vez al colmo de la insolencia. ${ }^{4}$

Bien se echa de ver que la novela ha sido escrita a vuelapluma, en un rapto de feliz inspiración, como las comedias que

en horas veinticuatro

pasaron de las musas al teatro. ${ }^{5}$

No era de suponer que Lope dedicase mucho tiempo a faenas pacientes de documentación sobre las cosas de Turquía. Lo verosímil era que, en este caso como en otros muchos, había echado mano de un libro porque le ofrecía hecho o casi hecho el relleno de sucesos históricos que necesitaba.

Hasta podía uno sospechar que el encontrar Lope un libro de historias turcas había sido la circunstancia capaz de fecundar su imaginación, sugiriéndole un esquema novelesco. Por eso es sorprendente que a ningún lopista se le haya ocurrido buscar la fuente de la erudición turca del Fénix. Hace algunos años, teniendo la obligación de estudiar La desdicha por la honra, acudí a la única edición anotada de las Novelas a la Señora Marcia Leonarda, ${ }^{6}$ y me llevé la decepción de ver que el comentario, prolijo en puntualizar alusiones perfectamente claras, nos dejaba a oscuras sobre este y otros puntos problemáticos.

Me quedé, pues, con mi sospecha sin comprobar, hasta que, el año pasado, al examinar un mazo de papeletas españolas extractadas del catálogo de la Biblioteca Nacional de París, tropecé zon al sítulo siguiente:

SAPIENCIA (Abbé Octavio). Nuevo tratado de Turquía, con una des cripción del sitio y ciudad de Constantinopla, costumbres del gran Turco, de su modo de govierno, de si palacio, consejo, mertyrios de algunos már. tyres ... Madrid (Viuda de A. Martín) 1622, in 4\%. El pie de imprenta del libro, publicado dos años antes que el tomo de lia Circe que contiene nuestra novela, y por la misma casa editora, lo designaba como la fuente probable de Lope. Y efectivamente, bastó hojearlo para encontrar largos párrafos utilizados o copiados en La desdicha por la honra. ${ }^{7}$

Pero hay más. Quien prosiģa en su lectura hasta las historias de martirios que cuenta el autor al final, llega a sospechar que una de ellas pudo sugerir a Lope la idea de llevar a Fclisardo a Constantinopla por una peripecia que no fuese la aventura tan trillada del cautiverio. Volveremos a analizar esta idea, bastante notable para dar su título a la novela. Contentémonos ahora con apuntar que Lope, fiel a su procedimiento de integral aprovechamiento de las fuentes, sacó del Nuevo tratado de Turquía no sólo su erudición acerca de los

4 Aspecto estudiado preferentemente por G. Cirot, en su interesante artículo Valeur litéraire des nouvelles de Lope de Vega (BHi, 1926, xxvin, pág. 332 y sig.). Véase nuestro Apéndice III.

5 Égloga a Claudio (ed. cit., pág. 434).

6 La de J. D. y L. A. Fitzgerald, en $R F$, xxxiv, 1913-15.

7 Véase el Apéndice. 
turcos, sino también datos esenciales para su enredo novelesco. Otros los sacó del repertorio cervantino.

Cervantes y Octavio Sapiencia: ¿inesperada combinación de fuentes dispares? La disparidad está en la fama póstuma más que en la experiencia personal de los dos escritores, pues ambos fueron cautivos de los turcos. Además, la combinación es lógica para quien piense en la fuerza del ejemplo cervantino para todo escritor español de novelas. Así como cualquier comediógrafo - y el mismo Lope - experimentaba la atracción de la comedia lopesca, obedeciendo a su tradición en el momento de bosquejar un esquema de comedia nueva, Lope, puesto a escribir novelas, no podía prescindir de Cervantes. El mismo Fénix lo había confesado, ${ }^{8}$ pocos años antes, al acometer por primera vez esta tarea a petición de la Señora Marcia Leonarda. Al probar este género de la novela corta, "más usado de italianos y franceses que de españoles," tenía conciencia de lanzarse a una empresa muy distinta de las de La Arcadia y El Peregrino. Era el mismo año en que Tirso de Molina sacaba privilegio para publicar Los cigarrales de Toledo. Lope no alude a las novelas del Mercedario, pero sí a las cervantinas, pues sabe que si España puede ufanarse de tener novelas "propias" es porque en este género "no faltó gracia y estilo a Miguel Cervantes." Reconoce "que son libros de grande entretenimiento y que podrían ser ejemplares como algunas de las historias trágicas de Bandello," aunque, para levantarse a tan alto nivel, las novelas cortas habian de ser obra de "hombres científicos o por lo menos grandes cortesanos, gente que halla en los desengaños notables sen. tencias y aforismos." Lope, secretario de magnates, se sentía dispuesto a en. mendar la plana al pobre diablo de Cervantes en punto a experiencia desengañada de la vida. No tenía la injusticia de negarle la maestría en el arte de contar. Cervantes había reivindicado la gloria de ser "el primero" que había "novelado en lengua castellana," escribiendo novelas suyas "propias, no imitadas ni hurtadas." 9 Había descubierto veneros típicamente españoles de novela corta: uno de ellos, el de la vida picaresca o apicarada contemplada con indulgente sonrisa (Rinconete, La ilustre fregona); otro, el de las aventuras de cristianos entre los turcos (El cautivo del Quijote, El amante liberal). Cervantes había hecho "suyo propio" este último género de novelas. Había vuelto a afir, mar su derecho de propiedad sobre estos temas al insertar La gran Sultana y Los baños de Argel (tan íntimamente relacionados con la novela del Cautivo) en su colección de Ocho comedias inéditas (1614).

En la tardía vocación de Lope como "novelador" interviene claramente el deseo de competir con Cervantes sobre el mismo terreno acotado por el manco de Lepanto y cautivo de Argel a costa de heroicas experiencias. Supliendo la falta de recuerdos personales con el donaire del relato, condimentando sus noticias de segunda mano con mucha sal y desengañados aforismos, quiere lucirse en historias de nobles españoles llevados por el destino a afirmar su valor entre turcos de Constantinopla o Túnez. No es casualidad el que, de las tres

8 En la primera página de Las fortunas de Diana, novela incluída en el tomo de La Filomena (Madrid, 1621).

9 Prólogo de las Novelas ejemplares. 
novelas incluídas en el tomo de La Circe, haya dos que acuden a estos temas: La desdicha por la honra y Guzmán el bravo. La ambición de contar aventuras de este tipo es probablemente el hecho primordial en la génesis de La desdicha. Del encuentro de esta ambición con el libro de don Octavio Sapiencia brotó la idea de nuestra novela, como brota la chispa del pedernal herido por el eslabón.

No habría surtido el mismo efecto un libro como la Topografía de Argel de Fr. Diego de Haedo (1612), colección densa de noticias fidedignas sobre la vida argelina y de datos exactos sobre cautivos cristianos de Argel, pero libro farragoso, atiborrado de consideraciones morales y religiosas, con sus autoridades al margen. Había en la Topografía de Haedo muchos párrafos capaces de sugerir ideas de comedias o novelas: véanse, si no, las líneas dedicadas a los compañeros de Cervantes, que, capitaneados por él, se escondieron en una cueva para fugarse cuando fueron vendidos. Las noticias de Haedo, más bien escuetas, abren ancho campo a la imaginación. Por eso mismo exigen un esfuerzo de elaboración por parte del que quiera utilizarlas.

En cambio el Nuevo tratado de Turquía, mucho más breve y apetitoso, ofrecía a Lope la inmensa ventaja de presentarse como una relación amena, rica en descripciones claras, en episodios animados como páginas de novela: tela muy a propósito para que un genial $f a$ presto cortase de ella los retazos nece. sarios para vestir parte de un argumento novelesco. Surgía el argumento en el mismo acto de la lectura, al fijarse la atención de Lope sobre los trozos aprovechables: descripciones de Constantinopla y del palacio del Sultán, historia del Sultán Amath y de su hermano Mustafá, favor y muerte trágica de Nasuf, yerno del Turco. Para convertir estos elementos en materia de novela ejemplar, bastaba que un héroe español fuese favorecido por una sultana de simpatías cristianas, y llegase a tanta privanza con el Sultán que a éste se le ocurriese casarle con su hija, ya viuda de Nasuf. El modelo cervantino de La gran Sultana sugería el tipo de la sultana favorita, de origen español, aficionada a ver representar por cautivos comedias españolas. Hacía falta, desde luego, preparar y explicar el salto mortal que da el español desde su patria y religión a la corte del Turco. La tradición de la comedia, juego de apariencias y disfraces, permitía salir airosamente del paso. Todo consistía en que el español se volviese turco, a lo menos en apariencia. El mismo Lope se divierte mucho con la facilidad de tal juego de manos:

Y aquí confieso a vuestra merced, Señora, que no sé, porque no me lo dijeron, cómo o por dónde vino a ser Felisardo nada menos que bajá del Turco, que parece de los disfraces de las comedias, donde a vuelta de cabeza es un príncipe lagarto, y una dama hombre y muy hombre, y a fe que dice el vulgo que no le hablen en otra lengua. Turco, pues, era Felisardo; no lo apruebo; sus opalandas traía y su turbante, y como era moreno, alto y bien puesto de bigotes, veníale el hábito como nacido . . .10

Con esta eutrapelia establece el narrador el nexo entre las dos partes de su novela. La unidad del personaje en sus andanzas sucesivas por Sicilia y

10 Ed. cit., fo $116 r^{\circ}$. 
Constantinopla resulta desde luego de su fe inquebrantable y de su valor, pero también, y sobre todo, de su presencia física, de los bigotes, que desempeñan tan gracioso papel en la riña con el Siciliano Alejandro, y cuyo dueño parece predestinado a llevar hopalandas y turbante. Es visible la fruición con que Lope bosqueja varias veces la figura de Felisardo vestido de turco, ya "con el turbante que coronaba de diversas plumas" 11 y en que traía las joyas regaladas por la Sultana, ya "recostado sobre una alfombra turca de rizos de oro entre labores de seda, puesto el brazo en dos almohadas de brocado persiano color de nácar" 12: que es como aparece, en la popa de su galera capitana, a los ojos de su amada Silvia y de su hijo, cuando caen en su poder con la tartana de un mer, cader calabrés ...

Pero hay que fijarse más detenidamente en la peripecia que hace posible la metamorfosis del caballero español en pirata turco. Felisardo pasa a Constantinopla a reunirse con sus padres, los cuales, a pesar de su nobleza y de su fe cristiana, han sido desterrados de España por moriscos. Se va porque le llena de vergüenza la sola idea de vivir af rentado entre cristianos viejos. ¿Será mera treta del novelista para saltar caprichosamente de la primera parte a la segunda? Ligereza sería pensarlo.

A Octavio Sapiencia le tocó conocer a Turquía precisamente en la época de la expulsión de los moriscos. Este clérigo siciliano, natural de Catania, cuenta que había estado cautivo en manos de los turcos en 1604. Después de la vida azarosa de los galeotes, recobró la libertad, al cabo de cinco años de cauti. verio, gracias al barón de Salignac, Embajador de Francia. Quedó todavía siete años en Turquía, al amparo de la embajada francesa: muerto Salignac en el ejercicio de su cargo, le sustituyó Achille de Harlay, barón de Sancy, ${ }^{13}$ pasando nuestro Sapiencia al servicio del nuevo embajador, que algunos años después había de ser gloria de la incipiente congregación del Oratorio. Es decir, que el siciliano vió desde el observatorio del cuerpo diplomático la vida de la corte turca entre 1609 y 1616. No es invención de Lope sino información de nuestro capellán lo que leemos en la novela acerca de los templos cristianos de Constan. tinopla, que "han intentado quitar los moriscos de la expulsión de España; y permitiendo el gran Visir que los derribasen y destruyesen por doce mil escudos que le daban, se fueron a despedir del Turco los embajadores de Francia, Alemaña y Venecia, diciendo que aquello era no querer paz con sus príncipes." 14 La lectura del libro de Sapiencia pudo de varias maneras sugerir a Lope la idea, no sólo de llevar a un español a la corte de Turquía, sino también de llevarlo allí a consecuencia de la expulsión de los moriscos. El clérigo siciliano cuenta

11 Ibid., f $117 \mathrm{v}^{\mathrm{Q}}$.

12 Ibid., $\mathrm{f}^{\circ} 118 \mathrm{r}^{\circ}$.

13 Sobre este personaje, que llegó a ser Obispo de Saint-Malo, véase P. Louis Batterel, Mémoires Domestiques pour Servir à l'histoire de l'Oratoire, éd. Ingold et Bonnardet, Paris, 1902, vol.1, pág. 212; y el vol. i de Les fameux voyages de Pietro DELLA VALLE, gentilhomme romain, surnommé l'Illustre Voyageur, Paris, $1663,4^{\circ}$. Della Valle estuvo en Constantinopla en $1614-15$ y trató allí al Embajador de Francia. 14 Ed. cit, fo 115 v? 
como testigo presencial la historia de un tal don Jerónimo de Urrea, en la cual intervino de manera tan directa que por milagro se libró de ser martirizado como él, y a consecuencia de su tragedia tuvo que huir de Turquía. Don Jerónimo, noble español oriundo de Zaragoza, tenía veintidós años cuando, en 1609 - el mismo año de la expulsión de los moriscos, - "después de haberse rescatado en Argel vino a la ciudad de Constantinopla a un negocio importan. tísimo." ¿De qué índole sería el negocio? "Por justos respetos" lo calla el historiador, probablemente bien enterado, pues don Jerónimo había venido a parar, como él, a casa del Embajador de Francia. Habiendo fracasado el joven aragonés en su empresa, no tardó el Sultán en apoderarse de él, sin que le valiese la protección del diplomático. Le hicieron turco por fuerza: renegó para salvar la vida y quedó adscrito al serrallo del Sultán, llegando a tener la dignidad de Agha. Pero interiormente siguió profesando la fe cristiana, como declaró a su amigo Sapiencia y como había de demostrar seis años después. En noviembre de 1615, con ocasión de un viaje de la corte, una riña con el caballerizo mayor le pone en trance de perder la vida. Le salva la intercesión de la Sultana. Condenado a servir en el ejército turco, sólo piensa en fugarse a tierra de cristianos con la complicidad de Sapiencia, que le proporciona pasaje en un galeón de Venecia. Pero don Jerónimo había tenido la imprudencia de fiarse de un criado suyo, morisco de los echados de España, que fingía ser cristiano, y le vendió. Le prendieron el 23 de febrero de 1616. Confesó su proyecto de volver a España, proclamando su resolución de morir por Jesucristo. Y por más que le instase un bajá a arrepentirse, prometiéndole el perdón y honores mayores que los pasados, escupió a la cara del bajá llamándole instrumento del demonio. Como a gentilhombre de palacio le cortaron la cabeza en vez de ahorcarlo o de echarlo al mar. Su martirio fué el 28 de julio de 1616.

¿Será arbitrario suponer que esta figura de noble español, con su voluntario y misterioso viaje a Constantinopla, con su aparente apostasía, con su privanza en la corte turca, y finalmente con su martirio, contribuyó a la concepción del personaje que Lope ideó al leer el libro de Sapiencia?

También contribuyó a la misma creación el recuerdo, más o menos preciso, de otro caso - ¿será realmente otro, o el mismo? - que hubo de ser muy comentado en la Corte. Se trata de un hijo natural del quinto Marqués de Villena, Duque de Escalona, don Juan Fernández Pacheco $(1563$, 1615), Virrey de Sicilia de 1606 a 1610. Nacido el 20 de septiembre de 1594, el mismo año del casamiento de su padre, don Diego Antonio Pacheco, tenía poco más de catorce años cuando se apoderaron de él los piratas argelinos cerca de Alicante, el 14 de octubre de 1608. Fué llevado de Argel a Constantinopla. Según Bethencourt, ${ }^{15}$ que nos proporciona estos datos, intervino Felipe III en las gestiones para su rescate, mandando a Constantinopla, en abril de 1612, a una persona especialmente encargada de ello, con carta para Tomás Glover, embajador del rey de Inglaterra. También llegó a proponer el canje del joven don Diego por el Bey de Alejandría; y habiendo fracasado la operación por

15 Francisco Fernández de Bethencourt, Historia genealógica y heráldica de la Monarquía española, vol. II, Madrid, 1900, págs. 246 y sig. y 253. 
la mala salud del Bey, ofreció el Rey de España, a principios de 1615, 20.000 ducados para ayuda del rescate. Terminan nuestras noticias con esta enigmática conclusión: "Llamáronle entre los turcos Anmat Bajá-Cheli. Murió cristianamente durante su cautividad, en 1616." Al conocimiento que tuvo Lope de esta historia verdadera debe atribuirse, indudablemente, la relación íntima que establece entre su héroe y el Virrey de Sicilia.

Pero, como insinuábamos, es casi seguro que la historia verdadera de don Diego Antonio Pacheco sea la única base de la historia de don Jerónimo de Urrea contada por Sapiencia. De está identidad de los dos personajes, Lope, que tal vez trató a Sapiencia en Madrid, pudo estar enterado. Y es punto capital para interpretar las intenciones, tanto del libro de Sapiencia como de la novela de Lope. No nos fundamos solamente en la coincidencia de las fechas los dos nobles cautivos llegan a Constantinopla en 1609 y mueren ambos allí en 1616 - , sino en el testimonio del propio embajador de Francia, protector de Sapiencia y de don Jerónimo, según el clérigo siciliano, y que intervino efectivamente en el asunto del joven don Diego. Está muy bien documentada la embajada del barón de Salignac en Turquía (1605-1610). Desgraciadamente para nosotros, la extensa relación manuscrita de Bordier, tan rica en pormenores curiosos y tan prolija en contar las cacerías del embajador, habla muy poco de su papel de protector de los cautivos cristianos. En cambio se conservan las cartas de Salignac a Enrique Iv. ${ }^{16} \mathrm{He}$ aquí lo que le escribe el 24 de julio de 1609:

El capitán de las galeras de Argel, llamado Jafer Ginovés, llegó aquí hace cinco días. Trajo a un hijo bastardo del Marqués de Villena, Virrey de Sicilia, el cual cayó preso al volver a España. La milicia de Argel le manda presentado al Gran Señor, que muestra tenerlo muy en grado. No sé cómo este mozo de catorce años había sido tan mal criado que de repente dejó su religión y renegó sin empacho alguno, a las primeras palabras que le dijeron. El padre ofrecía 50.000 cequíes por su rescate. Si se hubiera empeñado algo en no querer renegar su fe y creencia, quizá hubiera modo de sacarlo, pues la ley de ellos prohibe el usar fuerza para obligar a a razarla; y con parte del dinero que ofrecía el padre, era posible ganar la voluntad del Mufti para hacer alguna reclamación; pero ya no hay manera. Dos de los suyos, españoles, están retraídos en esta casa, y hago cuanto puedo para que sea notorio a todos el provecho que recibe la Christiandad de la amistad que Vuestra Magestad tiene con estas gentes.

La cosa ya no tenía remedio. Puede ser que seis años más tarde volviese el joven a la fe cristiana, que una pendencia con el caballerizo mayor u otro incidente le apartase del serrallo, surgiendo en él deseos de fuga coronados por una muerte cristiana... En 1609 se agrega "alegremente" a la corte del gran Turco, según afirma una y otra vez el barón de Salignac. Escribe éste al

16 Ambassade en Turquie de Jean de Gontaut Biron, baron de Salignac (1605 iे 1610). [II] Correspondance diplomatique et documents inédits publiés et annotés par le Comte Théodore de Gontaut B1ron, Paris, 1889, pág. 287 y sig. y 320 . La relación de Bordier ha sido extractada, nada más, por el mismo erudito en el primer tomo de su obra. Hemos consultado el manuscrito en la Biblioteca Nacional de Paris (Fr. 18076). 
rey de Francia el 2 de noviembre, o sea cuatro meses y medio después de llegar el joven a Constantinopla:

Ahora mismo acabo de recibir una carta del Marqués de Villena, Virrey de Sicilia, en la cual me habla de su hijo que fué traído aquí, rogándome con infinitas súplicas que, llegada la ocasión, ayude a su libertad, y anunciándome que pronto recibiré órdenes de Vuestra Magestad para ello. La cosa hubiera sido fácil si el mozo se hubiera aferrado algo a no querer dejar su religión; pero en el mismo momento de su llegada, abrazó la turquesca, y con tal alegría que no parece sino que venía desde hace tiempo firmemente determinado a hacerlo, de manera que son inútiles todos los medios para sacarlo de allí. Se ha vendido por hijo de una hermana del Rey de España, y con este motivo le tratan con alguna honra y respeto.

Y prosigue el Embajador narrando un caso paralelo, aunque bien distinto, por la resistencia del cautivo:

Estos días pasados prendieron en su posada al hijo mayor del Príncipe de Georgia, ${ }^{17}$ al cual mandó aquí hace pocos años su padre para que sacase al suyo, que lleva mucho tiempo encerrado en las Siete Torres. Pero los turcos los retuvieron a ambos. ${ }^{18}$ Este mozo, que no tiene aún catorce años, es de gentil ingenio y condición. Conocílo, pues vino a esta casa convidado a comer tres o cuatro veces. El gran Señor, pensando que este muchacho haría como aquel hijo del Virrey de Sicilia, le mandó prender y llevar al Serrallo, discurriendo que le sería de mucha honra el tener príncipes cris. tianos. Y así los tiene a ambos por renegados y esclavos suyos. Mandó emplear todo el primer día en pláticas con el mozo, para persuadirle a renegar como el Español, encareciendo la conducta de éste. Al día siguiente le quiso ver él mismo, mandando preparar varios vestidos muy buenos que darle, con una bolsa que tenía dos mil cequíes dentro; pero muy lejos de moverse el muchacho ni por promesas ni por ruegos, no quiso ver al gran Señor, diciendo y protestando que morirá de buena gana antes que renegar lo más mínimo de su fe y religión. Mandó el gran Señor que desde el aposento muy honrado adonde le habían llevado primero, le pasasen a otro muy pobre y ruin. Después no he podido saber lo que hace, aunque dicen que sigue en su resolución. Hace diez días que le llevaron al Serrallo. Si Dios le hace tanta merced que siga así, le dejarán libre sin duda; pues la fe de ellos prohibe expresamente el hacer fuerza. Bien es verdad que permite amenazar y amedrentar: pero nada más.

Es evidente que si el mismo año de 1609 hubiera llegado, también de Argel, otro noble español llamado don Jerónimo de Urrea, el cual, después de sustraído alevosamente a la protección de la embajada francesa, hubiera resistido cuarenta días a las amenazas de los turcos, que le decían que sólo saldría de allí renegado o muerto, no dejaría el embajador de poner en parangón su honrosa resistencia con la actitud del hijo del marqués de Villena, en vez de acudir al ejemplo del georgiano. La hipótesis que impone el cotejo de las cartas de Salignac con el libro de Sapiencia es que el clérigo siciliano compuso su historia de don Jerónimo de Urrea disfrazando el caso real de don Diego Antonio

17 País de religión cristiana griega.

18 Es decir: nieto y abuelo. 
Pacheco, envolviendo en misteriosos propósitos la llegada de su héroe a Constantinopla y atribuyéndole, al principio por lo menos, la firmeza de que dieron prueba otros cristianos, como el príncipe de Georgia; y si bien reconoce que don Jerónimo cae, "como frágil," renegando exteriormente, recalca la continuidad con que, en secreto, permaneció fiel al cristianismo.

¿A qué motivos obedeció el escritor al idealizar así la historia del joven noble español para insertarla en su libro? Quiso, desde luego, hacer un relato edificante; y, como Cervantes en su Cautivo, aunque más brevemente, compuso, a base de recuerdos personales, una novela ejemplar. También le interesaba, como a todo cristiano que regresaba de los baños de Argel y Constantinopla, afirmar públicamente que no había tenido complicidad con renegados. Era importante presentar a "don Jerónimo" como buen cristiano y auténtico mártir, pues éste, mientras estuvo en la "reclusión" del serrallo, "no tuvo otro amigo de confianza, por ser vasallo de la corona de España," sino a nuestro escritor. Además ¿quién sabe qué relaciones mediaron entre ellos antes de tal reclusión?

Cuando Salignac escribe a Enrique IV, a propósito del joven don Diego, que "dos de los suyos están retraídos en la embajada francesa", podemos suponer que uno de ellos es el propio Sapiencia. No abundarían los vasallos de Felipe III en la embajada de Francia por aquel entonces, antes de la reconciliación hispano-francesa de 1612-14, cuando Francia, como se ve por la correspondencia de Salignac y otras fuentes, cultivaba la amistad de los enemigos del rey de España, especialmente de los moriscos desterrados. Por fin, hay que pensar en los contactos que casi seguramente tuvo Sapiencia con el Marqués de Villena y su familia. Ésta, según los datos de Bethencourt, quedó convencida de que don Dieguito había muerto "cristianamente." Tal vez resultase agradable a los Pachecos la publicación de un relato idealizado de su aventura, en que su muerte cobraba el carácter de un martirio. El nombre supuesto de don Jerónimo de Urrea ${ }^{19}$ tenía la ventaja de no dar indiscreta publicidad a la desgracia del joven, sin impedir que, reservadamente, entre los

19 Más que por la semejanza con Ureña, uno de los apellidos primitivos de la familia del Marqués de Villena, creo que la elección del apellido se explica por el recuerdo de un personaje curioso a quien Sapiencia pudo conocer personalmente o de oídas: se trata del arabista español Diego de Urrea, que llegó a ser profesor de la Universidad de Alcalá "después de una vida aventurera pasada al servicio del Turco en Asia y África" (Nemesio Morata, Los fondos árabes primitivos de El Escorial, en Al-An, II, fasc. 1, pág. 101). Dice Diego de Urrea, recordando sus servicios en un Memorial dirigido a Felipe III: "Sabe muy perfectamente otras muchas lenguas como la Turquesca, Persiana y Tártara, en que también ha servido a Su Magestad, y conoce con verdad todas las cosas tocantes al estado de África y Asia, por haver sido muchos años secretario del gran Turco en las de África y Asia (por lo cual podría dar orden y traça cómo con facilidad la Africa viniese en poder de Su Magestad)." Escogido el apellido, pudo atraer el nombre de Jerónimo, por reminiscencia de don Jerónimo de Urrea, bastardo de la familia de los Condes de Aranda, hijo natural del último Vizconde de Biota, guerrero y escritor conocido entre los italianos tanto por su traducción española del Orlando furioso como por su Diálogo de la verdadera honra militar, obra publicada en Venecia (1566) y traducida al italiano por Alfonso de Ulloa (Venecia, 1569). Le sonaría bien a un italiano españolizado como Sapiencia. 
cortesanos enterados del caso, se acreditase la creencia de que el mártir don Jerónimo era el mismo don Diego Antonio Pacheco. Si la corte de Felipe IV hubiera tenido su Tallemant, quiza habría llegado hasta nosotros un eco de tan piadoso rumor.

Pero volvamos a Lope y a su novela. Es posible que, al hacer de su héroe un criado del Virrey de Sicilia, se dejara llevar de un vago recuerdo, de una asociación de ideas, quizá subconsciente, con un caso famoso, medio olvidado ya. También puede ser que no ignorase la relación existente entre don Jerónimo de Urrea y el hijo del Virrey don Juan Fernández Pacheco. En este caso, el secreto con que encubre no sólo el nombre de la villa castellana en que se cría su héroe, sino también los de los magnates en cuya casa sirve, y el de la corte italiana en que pasa el primer episodio, podría ser algo más que el clásico juego del novelista empeñado en crear, mediante tales precauciones, una ilusión de veracidad a favor de la historia narrada. No sería mero juego irónico la digresión sobre el peligro de escribir historia de tiempos presentes, aun en un caso como el de Felisardo, cuya desdicha "va a solas". Y la habilidad que tiene Lope, de introducir tarde y al descuido el título del Virrey, de nombrar a Sicilia aún más tarde, y como involuntariamente, todo ese aparato de trans. parente misterio ${ }^{20}$ serviría, ni más ni menos, para dar a entender a color che sanno que la novela de Felisardo tenía algo que ver con el desdichado vástago de los Pachecos. Todo sin desdoro de la ilustre familia, pues resulta gloriosa la conducta de Felisardo, y además aparece en la novela como protegido, no como hijo del Virrey.

Lope hace de su héroe un descendiente de los abencerrajes, que, de repente, siente su linaje entero deshonrado por la expulsión de los moriscos. ¿Quién sabe qué interés personal envolvía, para nuestro poeta, la situación del noble español que un día se ve despojado del orgullo de la sangre limpia? Es por lo menos curioso que haya tratado el tema cómicamente, en La villana de Getafe, ${ }^{21}$ diez

20 Véanse los pasajes aludidos. Fol. 109 v": "En una villa insigne del Arçobispado de Toledo, con todas sus circunstancias de grave, hasta tener voto en Cortes"; $110 \mathrm{r}^{\circ}$ : “. . aplicóse a servir en la casa de un Grande de los más conocidos destos Reynos, assí por Su ilustríssima sangre como por la autoridad de su persona ..."; "Mal he hecho en confessar que escrivo historia de tiempos presentes . . ." "deseos de aumentar honor y ver la hermosa Italia llevaron este mancebo a uno de los Reynos que su Magestad tiene en ella, en servicio de un Príncipe que avía de governarle . .." - Aparece por primera vez el título de Virrey, fol. $112 \mathrm{r}^{\circ}$, en la graciosa escena de los bigotes, y en el fol. $113 \mathrm{r}^{\circ}$ el nombre de Sicilia: ". . se partió de Sicilia. Dixe ya la ciudad? No importa, que aunque la novela se funda en honra, no vendrá por esto a menos, aunque fuesse conocida la versona..."

21 Ed. de F. Ruiz Morcuende, en Obras de Lope de Vega, publ. por la R. Acad. Esp. (Nueva edición Obras dramáticas, vol. x, Madrid, 1930). La comedia es evidente. mente posterior a la expulsión de los moriscos (1609) y anterior a enero de 1615 (según un documento publicado por San Román). Ruiz Morcuende no la cree anterior a 1613. S. G. Morley y C. Bruerton (Chronology of Lope de Vega's Comedias, New York, 1940, pág. 42) encuentran esta fecha algo tardía para las características de la versifi. cación, pero se limitan finalmente a señalar las fechas límites de 1610 y 1614 . Si, como sospechamos, La villana de Getafe guarda relación con pretensiones frustradas de Lope 
años, tal vez, antes de escribir La desdicha por la honra. En el acto segundo de la comedia se le ocurre a la saladísima villana Inés escribir estas mentiras a doña Ana para impedir su casamiento con don Félix del Carpio:

La lástima que os tengo, señora Doña Ana, me ha obligado a escribiros que este caballero con quien os casáis es morisco, y ansimismo lo es su criado; ya se les hace información para echallos de España. Su abuelo de Don Félix se llamaba Zulema, y el de Lope, lacayo, Arambel Muley, que eso del Carpio es fingido, porque con los dineros que ganó su padre a hacer melcochas en el Andalucía ha comprado la caballería con que os engaña." 22

El caso merece consideración, pues, aunque se trata de mentiras, no es éste un mero chiste como el de Morata, el gracioso de La inocente sangre, ${ }^{23}$ cuando, preguntado por el rey, responde que se llama Muley Arambel y nació en la Fuente del Saúco, país de excelentísimos melones, y, ante el asombro del rey, insiste en que esta Fuente es una villa de Marruecos . . . es decir junto a Medina de Rioseco. En La villana de Getafe las mentiras de Inés determinan todo el ulterior desarrollo de la acción, y estallan en el momento en que el protagonista está en vísperas de conseguir un hábito, mostrándose doña Ana convencida de

$$
\begin{aligned}
& \text { que es don Félix del Carpio la nobleza } \\
& \text { del mundo. }{ }^{24}
\end{aligned}
$$

Sobre todo, es indudable que hay una relación estrecha entre el protagonista y el autor de la comedia. Pues no se comprendería de otro modo el que el amo se llame don Félix del Carpio y el lacayo Lope, ni que el lacayo diga a su amo:

$$
\begin{aligned}
& \text { ¿No eres tú Carpio, sobrino } \\
& \text { del famoso don Miguel } \\
& \text { del Carpio, que hoy cuentan dél } \\
& \text { un valor casi divino? }{ }^{25}
\end{aligned}
$$

aludiendo claramente al inquisidor sevillano tío del poeta. Apenas puede

a un hábito, pueden señalarse contactos entre esta comedia y otra cuyo manuscrito autógrafo lleva la fecha del 20 de abril de 1615: El galán de la Membrilla. Aquí el galán se llama don Félix de Trillo; es noble y pobre y pretende un hábito que le niega el rey. Si se relacionan las dos comedias con un mismo incidente de la vida del poeta, será natural suponer que La villana de Getafe es muy poco anterior a 1615.

22 Ed. cit., pág. 393 b.

23 Bibl. Aut. Esp., vol. LII (Comedias escogidas de Lope, vol. Iv), pág, 369 y sig.

24 Ed. cit., pág. 392 b.

25 Ibid. pág. 390a. Petrov estudió las alusiones autobiográficas de nuestra comedia en las publicaciones de la Facultad de Historia y Filología de la Universidad Imperial de San Petersburgo (Zapiskí Istoriko-Philologicheskavo Fakulteta, 1907, tomo 82, págs. 471-480). Ruiz Morcuende volvió sobre el tema en el prólogo de la citada edición. Ultimamente se ha ocupado de este aspecto de La villana de Getafe Ricardo Del Arco y Garay en su obra La sociedad española en las obras dramáticas de Lope de Vega, Madrid, 1942, pág. 154 y sig. 
dudarse de que Félix del Carpio sea en esta comedia, como Belardo en otras, seudónimo autobiográfico de Lope. Y muy verosímil es que el padre de doña Ana, llamado Urbano, tenga algo que ver con don Diego de Ampuero Urbina y Alderete, padre de la primera mujer del poeta, ya que dice la maliciosa Inés, encareciendo la limpieza de sangre de la familia:

$$
\begin{aligned}
& \ldots \text { que estos hidalgos } \\
& \text { no van a caza con galgos } \\
& \text { que es su origen de Vizcaya, } \\
& \text { y son Alderetes finos. }{ }^{26}
\end{aligned}
$$

¿Querrá esto decir que la intriga de la comedia es autobiografía transparente del casamiento de Lope con Isabel de Urbina? No suelen ser tan sencillas las relaciones entre poesía y verdad. Pero si es de difícil solución el problema de la significación autobiográfica de La villana de Getafe, es extraño que, al plantearlo, no se haya señalado ${ }^{27}$ el problema psicológico y biográfico que entraña, por parte de Lope, el mero hecho de representarse a sí mismo enredado en calumnias contra su limpieza de sangre.

Sólo en 1627 pudo Lope "anteponerse el decorativo Frey" ${ }^{28}$ al recibir del Papa la cruz de San Juan. Es verosímil que en épocas anteriores, y tal vez aún después de ordenarse, haya sentido el prurito de conseguir un "hábito" español de Santiago o Calatrava. Si no lo consiguió, fué sin duda porque las pruebas de limpieza tropezaron con algún testimonio adverso a la hidalguía del linaje paterno. ${ }^{29}$ En esta hipótesis, se explicaría La villana de Getafe como protesta burlona del poeta contra los que frustraron sus esperanzas. El mezclar en el asunto a la familia de la difunta doña Isabel de Urbina, familia de nobleza conocida que le aceptó por yerno, equivaldría a una reivindicación indirecta de hidalguía. En todo caso, no se trata, como en La Dorotea, de una evocación poética y desinteresada del pasado. La cuestión de la ascendencia de don Félix está en primer término. $Y$ es notabilísima la insistencia con que varias escenas

26 Ed. cit., pág. 395b.

27 Petrov, cuyo estudio he podido leer con ayuda de mi amigo Mark Zaidelson, sospechó que hay en La villana de Getafe más secretos autobiográficos de lo que parece a primera vista. Mas no creo que acertó el lopista ruso al interpretar el personaje de Inés como reflejo de Juana de Guardo (por lo humilde del origen, desde luego, no por la picardía del carácter). Parece inverosímil que las alusiones transparentes de Lope a su primer matrimonio puedan tejerse con una intriga compuesta en lo mejor de las dichas del segundo, y para reivindicar estas dichas contra las ironías punzantes de Góngora (si no es que ya, segunda vez casado, quiera volver las torres en torreznos). El punto candente, ocasión inmediata de la comedia, se adivina tras la burla de Inés. Si protesta tanto el héroe contra la calumnia, si multiplica el poeta las alusiones complacientes a su tío el Inquisidor y a la nobleza de su primer suegro, es porque se pone tacha en la propia limpieza de Lope.

28 H. Rennert y A. Castro, Vida de Lope de Vega, Madrid, 1919, pág. 311.

29 Sobre esta discutida hidalguía, que Montalván califica piadosamente de hidalguía de ejecutoria, sobre el empeño que tuvo Lope de demostrar que la profesión de bordador ejercida por su padre era profesión hidalga como la de pintor, véase el artículo de A. Morel-Fatio, Les origines de Lope de Vega (BHi, vil, 1905, pág. 42 y sigs.). 
del acto III recalcan que el protagonista ha triunfado de la mentira, que "Madrid se ha desengañado", 30

$$
\begin{aligned}
& \text { que presto tendrá la verde } \\
& \text { o roja de Calatrava } \\
& \text { por servicios de sus padres } \\
& \text { y con papeles que bastan } \\
& \text { para mayores empresas... } 31
\end{aligned}
$$

Parece ser, realmente, que Lope de Vega se escandaliza con su héroe:

ique haya lenguas en el mundo que un testimonio levanten!;

que Lope triunfa con don Félix a la postre,

$$
\begin{aligned}
& \text { pues levantar testimonios } \\
& \text { es a veces levantar; } \\
& \text { que aunque padecen con ellos } \\
& \text { mientras no son conocidos } \\
& \text { muchos que estaban caídos } \\
& \text { se han levantado con ellos. }{ }^{32}
\end{aligned}
$$

Largo ha sido el rodeo para dar a entender que Lope, al hilvanar el argumento de su novela de La desdicha por la honra pudo ser llevado por motivos complejos y oscuros a hacer de su héroe un morisco ignorante de su origen: exigencias de un asunto hispano-turco, sugerencias del libro de Octavio Sapiencia, reminiscencia de La villana de Getafe, y ¿quién sabe? profundo resquemor de una herida de amor propio ...

Hay una antinomia asombrosa entre los encarecimientos que hace Lope del excelso valor de las novelas - "libros de grande entretenimiento y que podrían ser ejemplares" - y la despreocupación, rayana en descaro, con que escribe las suyas. Al fin y al cabo no es mayor esta oposición que la existente entre la devota intención que le lleva al sacerdocio y las cínicas confesiones de sus cartas al duque de Sessa. Gran parte del encanto del monstruo de la naturaleza consiste en la ingenuidad con que, siendo capaz de experimentar los sentimientos más nobles, adopta a menudo, en su vida y en su obra, la postura de la figura del donaire. ${ }^{33}$

¿Qué ejemplaridad puede haber, con esta disposición, en las novelas de Lope? Lo poco que exigen las tendencias psicológicas y morales del género, cuando Lope, figura del donaire, lo aligera por el gracejo para embelesar y divertir a la mujer amada. El milagro de estas novelas es la gracia desenvuelta con que, trazado el esquema de la historia, caminan del preludio al desenlace acogiendo "cuanto se viene a la pluma". En rigor, la génesis de la obra no acaba

30 Ed. cit., pág. 398a.

31 Ibid., pág. 396a.

32 Ibid., pág. 398a-b.

33 Pensamos en el artículo de José F. Montesinos, Lope, figura del donaire ( $C$ y $R$, números 23-24, febrero-marzo de 1935). La fórmula tiene aplicación mucho más general que la - muy aguda - que hace el autor al estudio del arte de La Dorotea. 
con la invención del argumento tal como resulta de unas operaciones casi instantáneas y de una gestación subconsciente: sigue a través de todos los pasos de que consta esta marcha de la redacción, a la vez certera y caprichosa. Creación tan libre de retoques que, si apareciera el manuscrito autógrafo, sería probablemente imposible decir si es borrador o copia sacada en limpio. Tan seguro es, en Lope, el arte de salvar cada escarceo de la fantasía y del humor.

Pero, entre estos escarceos, los hay que entrañan opiniones morales sobre pasos decisivos del protagonista. Aquí es donde, a pesar de todo, se impone la ejemplaridad propia del género novela ... Con tal que no se exagere la seriedad de la reflexión moral que manifiesta la novela de Lope. Nunca tienen sus comentarios el hondo acento humano que, al leer las novelas cervantinas, nos convida a formular la doctrina latente del autor. Sin embargo Menéndez Pidal ${ }^{34}$ advirtió el contraste entre la obra dramática de Lope, tan rica en dramas de honor que acaban con desenlace sangriento, y su novela de La más prudente venganza, en que proclama categóricamente: "He sido de parecer siempre que no se lava bien la mancha de la honra del agraviado con la sangre del que le ofendió . . ."; y explicó este contraste notando que "la novela, destinada a la lectura privada, invitaba a la reflexión condenatoria de una venganza sangrienta, mientras el teatro exigía entregarse a los sentimientos de mayor efectismo". Habría que ahondar más en lo que el mismo Menéndez Pidal llama el "carácter social de la venganza", que triunfa en la comedia; en tal examen no serían de despreciar las observaciones de Hartzenbusch acerca del más típico drama de honor conyugal, "obra no para la imitación sino para el escarmiento", ${ }^{35}$ y acerca de la reflexión condenatoria de la venganza san. grienta que asoma en las quejas del mismo héroe calderoniano que va a matar. Habría que recordar lo que nos dice el cuerdo Lotario en El curioso impertitinente de Cervantes acerca de la indivisión del honor conyugal entre los esposos, y de la "justa razón" por la cual "es deshonrado el marido de la mujer mala." 36 Podría tal vez, distinguiendo sucesivos estratos de moral social, restablecerse la unidad de la común conciencia moral que se expresa tanto en la comedia como en la novela: pues en ella descansan tanto los fallos someros del instinto social de venganza como los desenlaces de novelas cervantinas en que triunfa el perdón. Si no son "novelas de tesis" las cervantinas, mucho menos lo son las de Lope. Lo que nos interesa ahora es ver los límites de la reflexión moral en las novelas de Lope.

Dos son las Novelas a Marcia Leonarda que Lope fundó sobre "casos de la honra." En La más prudente venganza interviene la fatalidad social de la honra para impulsar al marido burlado a una serie de asesinatos disimulados. Condena Lope estos actos de venganza, como nota Menéndez Pidal, no por

34 Del honor en el teatro español, en De Cervantes y Lope de Vega, Buenos Aires. México, 1940, pág. 171.

35 Bibl. Aut. Esp., vol. xIv (Comedias de Calderón, vol. Iv), pág. 696b. Notas de A secreto agravio secreta venganza.

36 Don Quijote, 1a parte, cap. xxxill (ed. Rodríguez Marín, Madrid, 1927, vol. III, pág. 51 y sig.). 
creer, según la doctrina de los humanistas, que la honra verdadera consiste en la propia virtud, sino a consecuencia de un criterio social, porque cree que la honra fundada en la opinión, "para ser perfecta, no ha de ser ofendida". Además, ¿no será esta consideración la base de las venganzas secretas? También el héroe calderoniano llega a convencerse de que es contraproducente la venganza pública,

porque dijo la venganza

lo que el agravio no dijo. ${ }^{37}$

La solución discreta y cristiana, según Lope, es desterrarse, "perder la patria". Ya había dicho Petrarca algo semejante. ${ }^{38}$ Pero ¡qué nueva resonancia cobra en Lope la doctrina filosófica de la resignación a lo inevitable! Resonancia religiosa, por una parte: "ofrecer a Dios aquella pena," pensar que "por sólo quitarle a él la honra, que es una vanidad del mundo, quiere él quitarles a Dios si se les pierde el alma." . . . Pero al mismo tiempo, ¡oh colmo de mansedumbre evangélica!, "acordándose de que le pudiera haber sucedido lo mismo si en alguno de los agravios que ha hecho a otros le hubieran castigado; que, querer que los que agravió le sufran a él y él no sufrir a nadie, no está puesto en razón". 39 Esta exhortación al perdón recíproco, que a primera vista consuena con el precepto evangélico de amar al prójimo como a sí mismo, resulta ingenuamente picaresca cuando se trata de reciprocidad en el adulterio. Pensamos en los muchos maridos agraviados por Lope, en el propio marido de la señora Marcia Leonarda, tan agraviado en vida y muerte, hasta la grosera agresión póstuma de la dedicatoria de La viuda valenciana . . . Nos pareció escuchar la voz del sacerdote y hablaba la figura del donaire.

La desdicha por la honra nos presenta la fatalidad externa del honor encarnada en el prejuicio de la limpieza de sangre. ¿Cómo lo juzga Lope? En este caso también valdría la pena comparar el pensamiento de Lope novelista con el que se expresa en el teatro. Pero, aunque hablan poco de ella los que tratan del honor español, esta manifestación de la honra es mucho más típicamente española que las venganzas de los maridos calderonianos ${ }^{40}$ : y por esto tal vez no se atreve ningún dramaturgo a tratar el tema en serio, a escribir tragedias de la limpieza de sangre como hay tragedias del honor conyugal. Sin embargo, el tabú que parece pesar sobre tema tan candente no se aplica al género cómico. Personaje ridículo a todas luces es el rústico analfabeto, ufano de tener "cuatro dedos de enjundia de cristiano viejo rancioso sobre los cuatro costados de su linaje". 41 Y no sólo en Cervantes, que tiene fama justificada de escritor inde-

37 Calderón, A secreto agravio secreta venganza, jorn. III, esc. vili (Bibl. Aut. Esp., vol. vir: Comedias de Calderón, vol. I, pág. 607a).

38 Véanse los textos citados por AMÉrico Castro, Algunas observaciones acerca del concepto del honor en los siglos XVI y XVII, en la RFE, vol. III, 1916, págs. 357,386.

39 La más prudente venganza, en La Circe, ed. cit., fol. $135 \mathrm{r}^{\circ}$.

40 Ya mostró Menḱndez Pidal (ob. cit., págs. 180-182) la necesidad de ensanchar el estudio del honor, aunque no toca el punto que nos interesa aquí.

41 Frase del alcalde Benito Repollo en el entremés cervantino del Retablo de las maravillas (Cervantes, Teatro completo, vol. mi, Biblioteca Clásica, vol. cxcix, Madrid 1897, pág. 271). Sancho Panza las tiene comparables, aunque menos típicas. 
pendiente y reflexivo, sino en Lope de Vega, en Quiñones de Benavente, en toda la corriente de comedia y entremés que pone en escena a los "alcaldes encontrados", uno hidalgo y otro villano. ${ }^{42}$ Figurón ridículo es el primero, famélico, altanero y ufano de su ejecutoria; poco menos cómico en su agresividad es el segundo, que, seguro de su limpieza de sangre, tacha al otro de "judio". También hemos visto que Lope, en La villana de Getafe, convierte en tema jocoso la calumnia en materia de limpieza. Claro es que la comedia y el entremés sólo se burlan de los excesos y desviaciones del espíritu cristiano viejo. La "desdicha" de Felisardo, que voluntariamente se destierra a Turquía, a pesar de que un poderoso protector se ofrece a defender su honra, plantea de lleno el problema del valor de la limpieza de sangre. Es interesante ver cómo lo trata nuestra novela en las tres cartas cambiadas entre el héroe y su amo. Pues Lope cede la palabra a Felisardo y al Virrey.

Al propio Felisardo le toca exponer sobriamente su caso, en el cual Lope ha puesto toda la nobleza que cabe en un descendiente de infieles. Procede de los abencerrajes, de aquella aristocracia militar granadina que, en la tradición recogida por Pérez de Hita, aparece adornada con las más altas virtudes caba. llerescas, digna de fundirse con la caballería cristiana de los vencedores. Su familia es de los antiguos conversos de la conquista de Granada, es decir, de los que se convirtieron a raíz de la conquista. En fin, su nobleza de alma es igual a la de su linaje, pues deja el servicio del Virrey por temor de que des. lustren la casa de su protector los agravios que le puedan inferir a él mentando sus antepasados.

A tan hidalgo escrúpulo corresponde el Virrey comprometiéndose a imponer silencio a los malsines. Pero también justifica su manera de tratar a Felisardo por ideas generales que vale la pena poner en claro. No vacila en escribir que "en el nacer no merecen ni desmerecen los hombres, que no está en su mano; en las costumbres sí, que ser buenas o malas corre por su cuenta". Aristócrata filósofo, se adhiere, pues, a la doctrina eterna de los filósofos negadores de los privilegios de la sangre, ${ }^{43}$ y parece negar, de camino, toda validez al prejuicio de limpieza. Pero, a renglón seguido, parece decir el Virrey que el ser caballero pone a Felisardo por encima de las exigencias de este prejuicio. Alega el caso del Príncipe de Fez que, después de bautizado, ostentó "un hábito de Santiago a los pechos," y fué "tan honrado del rey Felipe II y de la señora Infanta que gobierna a Flandes, que él le quitaba el sombrero y ella le hacía la reverencia": caso inverso del de don Diego Antonio Pacheco en Turquía, y caso bien conocido de Lope, pues lo había celebrado en su Tragedia

42 La pareja de los alcaldes encontrados aparece varias veces en Lope. Con las típicas pullas contra el hidalgo judio en San Diego de Alcalá (Bibl. Aut. Esp., vol. L11, pág. 515), sin ellas en Los hidalgos del aldea. La serie de los entremeses de QU1Ñones DE BENAVERTE sobre este tema puede verse en el vol. il de la Colección de entremeses de Cotarelo en la Nueva Bibl. Aut. Esp. (vol. xvin). En los primeros reina (hasta la monotonía) la oposición entre el cristiano viejo y el judío. En los últimos se sustituye al tema del judío el del marido engañado. Curiosa equivalencia de dos iemas cómicos.

43 Véase, por ejemplo, Antonio DE TORquemada, Coloquios satíricos, en el vol. II de Orígenes de la novela (Nueva Bibl. Aut. Esp., vol. vil), págs. 542-547. 
del Rey don Sebastián y bautismo del Principe de Marruecos. ${ }^{44}$ Justifica el Virrey tan honroso tratamiento diciendo que "la diferencia de las leyes no ofende la nobleza de la sangre," lo cual equivale a reconocer que hay una nobleza musulmana como hay una nobleza cristiana, que tan pura es la sangre de la una como la de la otra, y que a un descendiente de nobles musulmanes, sobre todo más de un siglo después de la conversión de sus antepasados al cristianismo, nadie le debe pedir cuenta de su limpieza.

Así se reduce la filosofía formulada antes a un aristocratismo ecléctico. Actitud que bien pudo ser la de la alta nobleza española. Más segura de su nobleza que de su limpieza, en el sentido inquisitorial de la palabra, despreciaba por igual la hidalguía de ejecutoria y la limpieza, tan cacareada por los villanos (la comedia, cuando se burla de ambas, revela un vez más su inspiración aristocrática). Por lo menos el mismo noble que sin duda se avergonzara de confesar que una de sus bisabuelas era nieta de un tesorero judío proclamaba que no deslustraba a ningún linaje el entronque con los abencerrajes.

Es interesante leer lo que dice sobre la materia el jurisperito Juan Arce de Otalora, en su célebre tratado de la nobleza española. ${ }^{45}$ Muy firme en sentar la incompatibilidad de la nobleza con la sangre mezclada de moros o judíos, pone en duda los casos que se cuentan de confesos honrados por Carlos $\mathrm{V}$ y por sus antecesores. Niega que sobre privilegios concedidos a unos cristianos nuevos pueda fundarse una nobleza verdadera. Sin embargo, tratándose de descendientes de moros, no le parece ya tan absoluta la incompatibilidad. Otalora ha oído decir que la Chancillería de Valladolid admitió la nobleza de uno de ellos porque llegó a probar que pertenecía a uno de los linajes hidalgos de su nación "como fueron en África los Almorávides . . . y los Abencerrajes de Granada". Y confiesa que, en materia de conversos, es menos odiosa la raza mora que la judía, justificando la diferencia por la pertinaz ingratitud de Israel.

Ya se ve qué poco heterodoxa resulta, en un noble español, la doctrina profesada por el Virrey. El mismo Lope opina que Felisardo hizo mal en marcharse a Turquía y dice que, en Italia por lo menos, aunque fuese en los dominios italianos de la corona española, no corría peligro de ser tratado como morisco, pues el rey "sólo pretendió echarlos de aquella parte con que presumieron levantarse". Abona el novelador esta interpretación con las cartas del Venerable Don Juan de Ribera sobre la expulsión de los moriscos.

Pero las fantasmas del honor son aún más tiránicas que las leyes más inhumanas. Además, si se queda Felisardo a la sombra del Virrey, se viene la novela abajo. ${ }^{46} \mathrm{Y}$ Lope quiere hacer una novela exótica con ribetes de ejemplar.

44 Cf. el estudio de Menéndez y Pelayo (Prólogo al vol. Xil de las Obras de Lope de Vega publicadas por la Academia Española, Madrid, 1901, pág. CLIII y sigs., o vol. vi de los Estudios sobre el teatro de Lope de Vega, Madrid, 1927, pág. 185 y sigs.). Ro. dríguez Marín en su edición de Cervantes, Viaje del Parnaso, Madrid, 1935, pág. 417 , n. 1, dice que se practicaron en 1594 las pruebas del Príncipe de Marruecos para el hábito de Santiago y que se conservan en el Archivo Histórico Nacional de Madrid.

45 Summa nobilitatis Hispaniae (2a ed., Salamanca, 1559, págs. 187-194).

46 Recuérdese la donosa reflexión citada por Lope en Las fortunas de Diana, a 
Por eso triunfa la sensibilidad pundonorosa del héroe impulsándolo a desterrarse. Felisardo ganará en nobleza y en cristianismo a los cristianos viejos, realizando grandes hazañas por la misma religión de la cual parece despedido. Llegará a ser mártir y confesor del cristianismo . . . a trueque de hacerse turco, pues debemos suponer que habrá de ser circuncidado, y no por fuerza como don Jerónimo de Urrea. Pero éste es el paso escabroso que Lope salva con una pirueta. No hay que pedirle mayor profundidad de la que alcanzan las cartas de Felisardo y del Virrey. Llegar a plantear, con cuatro aforismos, el problema del noble morisco frente a los cristianos viejos, ya es algo ... Y lo urgente era ver a Felisardo en Constantinopla con sus hopalandas y su turbante, pues "como era moreno, alto y bien puesto de bigotes, veníale el hábito como nacido". Para Lope, idear un héroe no es meditar sobre un destino y una conducta, es percibir un gesto y trazar en el aire la línea quebrada de unas aventuras fulgurantes.

\section{APÉNDICES}

\section{TROZOS DEL NUEVO TRATADO DE TURQUIA APROVECHADOS POR LOPE}

La desdicha ..., ed. cit. fol. $115 \mathrm{r}^{\circ} \mathrm{v}^{\circ}$ [Descripción de Constantinopla]. Nuevo tratado..., fo 8 :

Las murallas tienen de circuito diez y ocho millas (que son seys leguas) y es. tán puestas en triángulo. En un ángulo está el palacio real, que mira al encuentro de Calcedonia (ciudad que fué en el Asia). El otro ángulo mira a mediodía y poniente, donde están las siete torres que sirven de fortaleza y cárcel mayor de la ciudad. Deste ángulo continuando siempre hazia tierra, se va al tercero ángulo, que está hazia la parte del norte. En este ángulo está el palacio antiguo del Emperador Constantino, en un sitio eminente, de donde se descubre toda la ciudad, en el qual nadie vive. Y desde este ángulo hasta donde está el palacio real del gran Turco, todo es puerto de una lengua ${ }^{47}$ de mar, que entra en la tierra tres leguas, y tiene de ancho media legua (llamado de los historiadores, por la abundancia que de todo tiene, Cuerno de oro), cuyo circuito está habitado de Turcos, Griegos, Armenios y Iudios, y no defendido a todos los vientos. Y desde el palacio real hasta el otro ángulo donde están las siete torres, el mar baña las murallas de la ciudad. Cerca de estas torres está el sitio de la antigua ciudad de Bizanziu ya destruyda, de la qual no parece otra cosa más que los cimientos de los arruynados edificios que deshazen los Turcos ...

propósito de las primeras palabras cambiadas entre Calisto y Melibea: “. . si Melibea no respondiera entonces ¿en qué, Calisto?, ni había libro de Celestina, ni los amores de los dos pasaran adelante."

47 Lope leyó equivocadamente legua. 
[ fo 9 v $^{0}$ ] Tiene la ciudad una altura en medio, donde está la calle mayor, que comiença desde el Palacio real hasta la puerta que llaman de Andrinopoli, y en la dicha calle (por ser lugar eminente) ay muchas mezquitas, y entre ellas algunas suntuosas, edificadas por los grandes Turcos passados, como fueron Sultán Hagmeth, Sultán Bayesith, Sultán Murath, Sultán Salim y otros: pero la mayor, más rica, y edificada en mejor lugar,

[fo 9 rọ] es la Solimania que edificó Sultán Solimano, intentando auentajarla a la Iglesia de Santa Sofia.... [sigue la historia de la Solimania, edificada con columnas y piedras de monumentos antiguos]

... Dentro de la ciudad ay muchas pirámides y colunas del tiempo de Constantino, sobre las quales huuo estatuas [estas estatuas fueron echadas por tierra después de la entrada de Hagmeth en 1455. Sigue la descripción de las colum. nas más notables:]

...y después la del Emperador Constantino [no habla el autor de sus esculturas, como en la descripción de la llamada Columna Historial, en que está esculpida la historia de una victoria del Emperador Arcadio]

[fํ $9 \mathrm{v}^{\circ}$ ] ... En la dicha ciudad ay los Bisisteri, que son quatro Serrallos fortíssimos, con sus puertas de hierro techados de bóveda cubierta de plomo; los quales tienen sus guardas de noche, y en ellos suele auer mucho dinero, y estar todas las mercaderías más ricas de oro, plata, y joyas de la ciudad, y de todo género [fo $10 \mathrm{r}^{\circ}$ ] muy grandes riquezas. Ay Serrallos de mercaderías, (que llaman Caravassará) donde viven todos los mercaderes estrangeros. . . .

Está también en este lugar de los Bisisteri el mercado donde se venden todos los esclauos Christianos y renegados, que mueve a gran compassion ver tanta miserable gente, hombres, mugeres, y de todas edades, muchachos y muchachas, todas naturales de aquellas partes de Roxia, Moscovia, Jiorgia, Men. grilia, Circasia, Polonia, y de otras partes: pero de los nuestros de Poniente, raras vezes los ay en aquel mercado: porque los estiman mucho a causa de tenerlos por de mejor entendimiento, y más valor que los de las otras partes, y por esto luego hallan dueño. Y suele aver en aquel mercado número de mil, y dos mil algunas vezes, teniéndolos allí como bestias, y quien los quiere com. prar, los haze desnudar para ver si tienen algun defeto... [Sigue el autor dando más detalles]

[fo 8 vo] Las murallas de la ciudad son del tiempo y fundación de Constantino... Por la parte del Norte ai en ellas doze puertas, que todas miran el puerto. Por la parte de poniente ay siete puertas que miran la tierra. Por la parte de mediodía ay otras doze puertas que están frontero de la mar: y todas las dichas puertas que son treynta y una, de día están abiertas con guardas de porteros y Genízaros ...

[fo $\left.11 \mathrm{r}^{\circ}\right]$... Las Casas en la dicha ciudad, no las usan más altas que de dos suelos, fabricándolas con mucha madera ...

Los Turcos no usan tapicerías en sus casas, solo las adornan con techos 
dorados de grandíssimo artificio de pintura de follajes peregrinos, que llaman grutarìà....

[fo $\left.39 \mathrm{v}^{\circ}\right]$... Ay en Constantinopla entre Cayques y Permas, que son bar. cas pequeñas que suelen passar la gente de una parte a otra de la mar, al pie de doze mil...

[fo $11 \mathrm{v}^{\circ}$ ] El temple de Constantinopla està en quarenta y tres grados, es frigidissimo, y desde el primero de Deziembre hasta el fin de março está siempre cubierto de nieve. ...

[en el párrafo anterior enumera el autor las iglesias cristianas:] ... tenemos una Yglesia Latina con una Devotissima y milagrosa imagen de nuestra Señora, que llaman de Constantinopla, de pinzel; y otra Yglesia de San Nicolas en la qual ofician los Latinos [siguen algunos detalles más] leemos:]

[Mucho más lejos, en el cap.xx (De la ciudad de Pera y sus Yglesias),

[f $\left.54 \mathrm{v}^{\circ}\right]$ Las demás iglesias por particular merced de Dios permanecen oy, las quales los Moriscos rebeldes de España, que aportaron a vivir a Constantinopla, procuraron, y ofreciendo doze mil ducados al gran Vecir, que las quita. se a los Católicos, y se las diesse a ellos para hazer sus Mezquitas. Mas aunque el Vecir ya lo concedía, los Embaxadores Christianos, como de Alemania, Francia y Venecia, sabiéndolo se fueron juntos, y hizieron instancia al Vecir, diziéndole que queriendo quitar las Yglesias a los Catolicos era una expulsión de todos los Embaxadores Christianos, quebrando la paz con el Emperador, Rey, y Republica, con que el Vecir desistió de su bárbaro intento.

La desdicha, fo $116 \mathrm{r}^{\circ}$ [Historia de Sultan Amath y de su hermano Mustafá]. Nuevo tratado, fo 18 vo y fo $21-22$ :

[fo $18 \mathrm{v}^{\circ}$ ] El gran Turco passado, padre del que oy reyna cuyo esclavo fuy, se llamava Sultan Amath; en el tiempo que me huy de Constantinopla, que fue el primer día del mes de Março de 616, tenía treynta y tres años . . .

[f? $21 \mathrm{r}^{\circ}$ ] . . El gran Turco passado, padre del que oy reyna, tuvo un hermano que oy dizen vive, de edad como de treynta y tres años, y se llama Sultan Mustafá, a quien ha tenido siempre preso. Es hombre eminente en saber su ley, como observante en guardarla, en cuyo estudio ha sido muy vigilante. El Rey intentó muchas vezes matarle, como por su ley, y razón de estado, se acostumbra matar los hermanos quando los Reyes tienen hijos varones. $Y$ avrá diez años que estando [21 $\mathrm{v}^{\circ}$ ] preso el dicho Sultan Mustafá dentro del proprio Palacio para darle la muerte, una mañana auíendo ydo el Secretario y jardinero mayor del Rey, que llaman Vostangibaxi, con otros ministros, para executar la orden del gran Turco y de su Consejo, hallaron la cárcel cerrada, y al dicho Sultan Mustafá fuera della, passeándose por un jardín; al qual bolvieron a la prision. Sabido esto por el gran Turco, se admiró de manera que, pareciéndole mi- 
lagro, revocó el orden de muerte, aunque le dexó estar preso. Pero de nuevo aconsejado del Muffiti, que es cabeça de su ley, determinó segunda vez que muriesse su hermano, mas la siguiente noche le apareció en sueños un hombre armado con una lança en la mano, amenazándoles, y por este temor dexó con vida a su hermano. Otra vez instando el dicho Muffiti y su Consejo que la vida de su hermano auía de ser su muerte y destruyción del Imperio, el gran Turco se determinó un día de matarle él mismo: y assí queriéndole tirar una flecha en tiempo que el preso passeava por un jardín de su reclusion, fue tal el temblor que sobrevino al Rey, que se le cayó el arco de las manos, con que quedó vano su intento, como de nuevo en su punto la admiración. Parece que Dios a este Príncipe, aunque bárbaro, le ha querido por sus secretos juyzios conservar hasta oy la vida

Es tan humilde, que embiandole el gran Turco vestidos de brocado finíssi, mo, y otros riquissimos dones, y ofreciéndole mugeres, dezía que para él era demasiado un vestido ordinario, y un pedaço de pan para passar el resto de su vida, mientras Dios y su Magestad fuessen servidos de dexarle con aquella en [22 $\left.\mathrm{r}^{\circ}\right]$ aquellas quatro paredes. Y assí el gran Turco haziendole dar su plato ordinario con puntualidad, le dexó vivir

El Gran Turco Sultan Amath tuvo muchos hijos varones y hembras, de los quales solo víamos quatro, dos varones y dos hembras ... [no habla el autor de la reclusión de los demás, ni de la creencia de que Mustafá ha de heredar a su hermano].

La desdicha, fo $116 \mathrm{r}^{\circ}-\mathrm{v}^{\circ}$ [Afición de Sultan Amath a los retratos de Cristianos]. Nuevo tratado, fo $19 \mathrm{r}^{\circ}$ :

[fo $19 \mathrm{r}^{\circ}$ ] Era inclinado el dicho gran Turco a imagines y retratos de Christianos, aunque ellos no las acostumbran ni las hazen. Embiaua diversas vezes a pedirlas al Embaxador de Francia, y después de auerlas visto se las bolvía. [No se trata de retratos de reyes o nobles españoles; sin embargo, nótese que en otro lugar alude el autor a la consideración del Sultán por los príncipes de la Casa de Austria:]

[fo 36 v $^{\circ}$ ] Aborrecía a los Embaxadores de Príncipes Christianos que en tonces residian en Constantinopla. Pero un día les dixo a todos juntos en mi presencia, dando audiencia general en la gran sala de su Palacio, que quería hazer paz con la casa de Austria, reconociendo que los della eran Príncipes verdaderos, en cuya comparación los demás eran nada. . . .

La desdicha, fo $119 \mathrm{r}^{0}-120 \mathrm{v}^{\circ}$ [Historia de Nasuf]. Nuevo tratado, fo $34-36 \mathrm{v}^{\circ}$ :

[Cuenta el autor el origen de Nasuf Baxá, sus campañas en Persia, terminadas por una paz victoriosa, tal vez "disimulada", su casamiiento con la hija del Sultán] 
[35 r\%] A 22 de Setiembre año de 1612 entró en Constantinopla Nasuf Baxá primer Vecir con grandissimo aparato, volviendo de Persia con el exercito de que era general (después de aver hecho las paces con aquel reyno) con dozientas y sesenta y quatro azémilas cargadas de moneda en oro y plata suyo.

A 17 de Otubre 1614, que fue Viernes, a hora de vísperas, por orden del gran Turco, cuyo yerno era Nassuf, le cortaron la cabeça. La causa dezían que avía sido Mamuth Baxá, hijo de Cigala: porque siendo el dicho Mamuth Baxá gobernador en los confines de Persia, después que Nasuff Baxá se bolvió con el exército a Constantinopla, diziendo que avía tratado paz con el Persa con ánimo traydor, y que por cautela traía consigo el Embaxador Persiano que desde allí venía con Nasuff con muchos dones, como diré adelante, El Persiano, no obstante la paz, aun conquistava tierras del Turco; y el Mamuth escribiendo sobre esto a Nasuff Baxá jamás tenía respuesta. De que coligiendo Mamuth que Nasuff tenía trato con el Rey de Persia, y que la paz era falsa, se partió para Constantinopla, y en cl viaje le ocurrió un ministro como Alguazil Real (que llaman Chiaux), embiado por el dicho Nasuff, con cartas para las tierras confines de Persia. A este combidó Mamuth de industria a que se quedasse aquella noche en su posada, persuadiéndole con que era ya tarde para alargar la jornada. Y aviéndose quedado, le hizo dar de cenar espléndidamente. Acabada la cena, obró cierta cosa que le dieron, con que se quedó dormido; y assí le quitó Mamuth las cartas que llevava, y halló en ellas algunas para las correspondientes de Nasuff en los confines de Persia, y para el rey de Persia, tratando todas trayción contra el gran Turco. Ufano desta presa, hizo matar al Chiaux ministro desta trayción con llevar aquellas cartas, y enterrarle dentro del propio pavellón donde el mismo difunto dormía. Prosiguiendo el viaje, llegó a Escuteret en el Asia cerca de Constantinopla, y aviendo avisado a Nasuff de su llegada, le respondió el mismo que no entrasse en Constantinopla, pues avía venido sin licencia. Tres días después embió Mamuth a pedir de nuevo licencia para entrar: pero Nasuff le respondió que, si quería entrar, que le embiasse treynta mil cequíes de oro de presente. Pero hallándose Mamuth casado con una Sultana hermana del gran Turco, aunque no habian cohabitado, y sabiendo ella que su marido estava tan cerca y no entrava a verla, se resolvió de yr a verle, como lo hizo. Y sabido de su esposo el agravio que le hazía Nasuff, y el negocio tan importante que tenía que tratar con la persona real, se partió luego la Sultana y fué a hablar al Rey su hermano, el qual, aviendo oydo quanto la Sultana le dixo, embió de noche secretamente su fragata por el dicho Mamuth, que entró en Palacio por una puerta falsa, porque no fuesse visto. De las cartas que mostró al Rey se descubrió la trayción de Nasuff Baxá: y buelto Mamuth donde estava, dissimuló por algunos días el gran Turco traçando el modo de quitar la vida al traydor, recelando no se passasse al Asia donde tenía gran poder. $Y$ ultimamente, esperando que fuesse al Consejo donde le pensava dar muerte, el dicho Nasuff, o por indisposición, o por algun rezelo, faltó tres días del Consejo: y preguntando el gran Turco como su primer Vecir no yva al Consejo, le respondieron que estava indispuesto, y assí el gran Turco fingió querer yr a visitar su hija y muger de Nasuff a su 
casa, y cerradas las cortinas del coche, ${ }^{48}$ de manera que se creyesse que yva dentro el Rey, embió a su Secretario de Cámara con algunos criados de Palacio, hombres fortissimos, ${ }^{49}$ y un decreto en el qual pedía a Nasuff el sello del officio de primer Vecir, y con otro decreto le pedía su cabeça. Llegaron a casa de Nasuff a tiempo que ya estava la casa cercada de dos mil hombres. creyendo que fuesse el gran Turco. El Secretario y ministros se apearon, y yvan cerrando las puertas hasta que llegaron al aposento donde estava Nasuff solo con dos Eunucos, que la demás familia estava fuera. A estos mandó el Secretario que saliessen fuera; y haziendo acatamiento a Nasuff le presentó el decreto del Rey en que le pedía el Sello. El qual maravillándose dixo: El gran Turco tiene mejor hombre que yo que pueda hazer este officio. Entregó el sello: y luego el Secretario le manifestó el otro decreto en que le pedía la cabeça. Oyendo esto començó a suspirar, turbado, a dar vozes, diziendo: Qué he cometido contra el gran Señor? qué trayción es esta? Al fin resuelto a morir pidió que le dexassen hablar con su muger, que estava en otro quarto; y, no queriéndoselo conceder, pidió que le dexassen lavar, y hazer el zalá su oración; y concediéndoselo estuvo tan turbado que no lo pudo hazer; y estando ya dispuesto a morir, se assentó con grandíssimo dolor. El Secretario y sus ministros le miraban sin tener ánimo de executar la sentencia: y, viéndolo Nasuff, ya de temeroso temerario les dixo: Canalla, qué estays mirando? Hazed vuestro oficio. Con que animados quatro dellos le dieron garrote. Después el Secretario, que llaman Vostangibaxi, dexando cerradas todas las puertas y tomadas con guardas, fué a dar aviso al gran Turco como quedaba executada su orden. El qual no queriendo creer, le mandó que traxesse la cabeça y assí bolvió y se la traxo. Quando el gran Turco la vió, la mandó arrojar en el suelo, donde pisándola dixo: "Bre Cayn" que es lo mismo que "traydor." Toda la hazienda del dicho Nasuff, que en dineros, joyas y otras cosas fueron sin número, se confiscó para el gran Turco, aunque lo que se halló en el quarto de su muger quedó para ella. Halláronle mucha cantidad de armas, y entre ellas mil y dozientas espadas, todas lindíssimas, guarnecidas de oro fino y de plata y mucha armería para caballos. Hallóse que tenía a su devoción dentro de Constantinopla 30.000 hombres todos assalariados; dava cada día cevada para 7.500 cavallos. $Y$ assí por lo que se vió exteriormente, no ay duda que si se huviera vivido algun tiempo, para las fuerças que tenía y del modo que avía proveydo sus cosas, se huviera coronado Rey de toda la Asia.

La desdicha, fol. $120 \mathrm{v}^{\mathbf{0}}-121 \mathrm{r}^{0}$ [Descripción del palacio real].

Nuevo tratado, fol. $16 \mathrm{r}^{\circ}$ :

[Describe el autor el recinto del palacio con sus] fuertes y altos muros

48 No habla el autor de lienzos dispuestos para que no sea visto el Sultán. Sólo dice en otro lugar $\left(f^{\circ} 21 \mathrm{r}^{\circ}\right)$ : "Tiene obligación el gran Turco de dexarse ver del pueblo una vez en la semana o en la mar o en la tierra, assi establecido por su ley. Y quando salía Sultan Amath en Viernes, que es su fiesta (como el Domingo a los Christianos) y yva a hazer el zalá (que es su oración) ya en una mesquita ya en otra, llevava delante de sí dos hijos suyos a cavallo ..."

49 En otro lugar nombra el autor a los ayamolanos. 
torreados de vistosas torres. Tienen de circuito los dichos muros dos leguas, y ay en él ocho puertas: quatro dellas miran a la marina, y quatro a la parte de tierra. Está situado este Palacio en uno de los ángulos ya dichos de la ciudad, el qual está por la parte de Levante mirando al sitio de la antigua ciudad de Calcedonia . . . después de cuya destruyción ocupa aquel lugar una aldea. Por la parte del mar al pie de los dichos muros, ay una gran corriente de agua con fluxo y refluxo, y tan copioso que algunas vezes pueden entrar las galeras. Ay cincuenta pieças de artillería de bronze plantadas, que guardan el mar por la parte de fuera, sin otras 200 que están en el suelo desencabalcadas. Ay otras 15 pequeñas ...

[ $\left.16 \mathrm{v}^{9}\right]$ De las dichas puertas la mayor está por la parte de Poniente, mirando la yglesia de Santa Sofía que diré. En entrando por la dicha puerta a mano derecha ay un hospital para todos los enfermos de Palacio de qualquiera calidad que sean (y le llaman Timarina). Este hospital está guardado y gover. nado de Eunucos blancos. A mano izquierda está la yglesia antigua de San Jorge, dentro de la qual están todas las armas del Turco. Más adelante, que se llega a la segunda puerta donde se apean los que acuden al Consejo, ay una calle anchíssima larga media milla, y por la parte de Tramontana ay una puerta por donde entra y sale la gran Sultana y todas las damas y criadas suyas del Serrallo. Entrando la segunda puerta, ay un jardín quadrado, muy espacioso, con muchos árboles, y un parque con algunos venados. A mano derecha ay una gran plaça cubierta donde suele estar la guarda de Genízaros, y comer los días de Consejo. Porque los otros días quedan de guarda assí en la primera como en la segunda puerta doze porteros (que ellos llaman Capigi) en cada una. Por la parte de Mediodía están las cozinas reales y de la familia de Palacio, mas no para las mugeres, porque tienen sus cozinas aparte. $Y$ toda la multitud de Consejeros, Genízaros y oficiales, en el dicho día de Consejo, suelen comer ordinariamente en Palacio. En las quales suele assistir tan grande número de cozineros, que pareçe increyble: porque es assentada opinión que entre maestros y officiales son quatrocientos y noventa, que todos juntos sirven los días de ostentación, pero de ordinario sirven setenta en setenta cada semana.

[ $17 \mathrm{r}^{\circ}$ ] Corresponde a la dicha puerta la que es tercera dentro de la casa real: la qual guardan Eunucos blancos, y por ella no puede entrar persona alguna que no sea de la familia real (aunque sea Vezir) sin orden del Rey.

\section{HISTORIA DE DON JERONIMO DE URREA}

Nuevo tratado, fo $65 \mathrm{v}^{0} .68 \mathrm{r}^{\circ}$ (Cap. XxvII, $\left.\$ \S I I-\mathrm{VI}\right)$

[fo $65 \mathrm{v}^{\circ}$ ] II. En el año de 1609, siendo Embaxador ordinario de Francia Monsieur de Saliñat, en la Corte del gran Turco, llegó allí un moço como de veynte y dos años llamado don Geronymo de Urrea, hombre noble, natural de Zaragoça de Aragón, el qual después de auerse rescatado en Argel, vino a la ciudad de Constantinopla a un negocio importantíssimo (el qual por justos respetos callo). Siendo pues buen Católico, y persona de talento, antes de 
desembarcarse escriuió al Embaxador Francés, pidiendole le hospedasse en su casa. El Embaxador embió luego su mayordomo, intérprete de la lengua, dos Genízaros, criados de casa, y a mí que era su Capellán, al baxel de donde desembarcamos a este Cauallero como libre, y le acompañamos hasta la casa del Embaxador, el qual le recibió con mucho agassajo, y comunicado el intento que lleuaua, le quiso executar: pero en vano, porque no tuvo efeto, [66 $\mathrm{r}^{\circ}$ ] con que desengañado dessistió, queriendo boluerse a España: pero por falta de passaje estuuo quatro meses regalado del hospedaje. En el interin teniendo aviso el gran Turco, que el Embaxador de Francia tenía este moço español en su casa, embiósele a pedir. Pero el Embaxador negó primera y segunda vez que no tenía tal persona. A la tercera el gran Turco embió ciertos ministros de su Corte, diziendo al Embaxador que le embiasse el Español para solo verle, que luego se le boluerían, y que de hazer lo contrario, perdería su gracia, y de su mismo Rey. Con esto el Embaxador se le embió, creyendo se le boluerían: pero engañóse, porque luego que don Geronymo entró en palacio donde ya le esperauan algunos criados del Rey, le arrebataron en peso, a unque él siempre daba vozes, diziendo que no quería ser Turco; y assí viendo los compañeros esta trayción hecha al Embaxador, y la violencia que se hazia al Cavallero, se bolvieron a dar la mala nueva al Embaxador. El qual, por no lo poder remediar, se afligió mucho, pero más el paciente, que le tuvieron aquellos malditos en continuo aprieto casi quarenta días, diziéndole siempre el Eunuco mayor de Palacio, que avía de salir de allí, sino renegado, muerto, y a esta exorbitancia le movía cierto intento que no conviene escriuir. En fin oprimido de los Turcos, como frágil cayó renegando, mas no interiormente. Fué circuncidado, y llamado Morath; pero en secreto siempre professó la Fe Christiana, como se vió por experiencia en el año 1616, a 28 de Julio, que sucedió lo que se dirá adelante.

[fo $\left.66 v^{\circ}\right]$ III. En todo el tiempo que este preso estuvo en esta reclusión no tuvo otro amigo de confiança, por ser vassallo de la corona de España, sino a mí; y assí me escrivía de ordinario, dándome cuenta de su amarga vida. Yo le respondía consolándole, y exortándole a la devoción que debe un Christiano, encomendándose siempre a Dios, y professando interiormente la santa $\mathrm{Fe}$ Christiana, y que confiasse de su misericordia que vendría el tiempo de su libertad. Después tuve inteligencia para hablarle algunas vezes en esta conformidad, aunque con mucho riesgo mío.

IV. Año de 1615 en el mes de Noviembre, passando el gran Turco con toda su Corte, y familia por el Asia a la ciudad de Cuña, el camino, como de invierno, era muy malo, y algunos criados del Rey yvan a pie, entre los quales era uno don Geronymo, a causa del poco cuydado del Cavallerizo mayor, siendo suyo el cargo de proveer toda la familia real de cavalgaduras.

Enojados desto los que padecían aquella falta, riñeron con el Cavallerizo, y derribándole de su cavallo, le dieron muchos palos, de lo qual indignado el gran Turco, mandó que luego diessen muerte a don Geronymo y sus compañeros. Mas después, a instancia de la gran Sultana, se les perdonó con echar de Palacio seys de los que fueron culpados, uno de los quales fué Don Gerónymo, y se le 
dió su plaça a cada uno de veynte aspros cada día para servir en la guerra. Mas como Don Geronymo no desseava otra cosa sino de librarse del Serrallo donde le tenían, luego que salió me vino a buscar, instándome le traçasse passaje a la Christiandad, lo qual procuré con harto cuydado [fo $67 \mathrm{r}^{\circ}$ ] fletando en el galeón Balbi de Venecia. Y porque Don Gerónymo se fiaba de un Morisco expelido de España, que tenía por criado, el qual dezía que era Christiano, pensando embarcarle consigo, el Morisco siempre dissimuló, $y$, pocos días antes de la partida, yéndose al Palacio del gran Turco, reveló lo que passava, dándome a mi por autor de aquella huyda. Con esto dió orden el gran Turco que me prendiessen a mí primero y después a don Gerónymo. Pero no hallándome a mí por la ciudad, y dudando no se fuesse don Gerónymo conforme a la información de su criado, prendieron a él primero a 23 de Febrero 1616. El qual luego confessó que era verdad que quería venirse a España a morir Christiano, y que yo le ayudava; pero, pues no avía podido venir a morir a la Christiandad, estava promptíssimo a morir como Christiano en Constantinopla, porque le avían hecho Turco por fuerça, $y$, aunque él avía traído el hábito de Turco, siempre avía tenido a Christo en el coraçón, y estava resuelto a morir por él. Oyendo esto el Baxá, embió ocho Turcos por mí en casa del Embaxador de Francia (a quien entonces yo servía de Capellán y confessor) para prenderme y empalarme luego. Pero Dios no quiso permitirme aquella dichosa muerte, antes me libró de las manos de aquellos perros, que me tenían asido de la barba, ayudándome la familia del Embaxador de manera que dieron a los Turcos muchos palos: por lo qual el Baxá se mostró grandemente ofendido del Embaxador, y dava vozes contra mí toda la Corte dizíendo: Crucifíquenle. El Embaxador se fue al Baxá por remediar el alboroto. Mas el Baxá, después de averle hecho esperar dos horas a su puerta, porque no me llevó a mí consigo, no le quiso dar audiencia, sino que le embió a dezir que, si estimava la gracia del gran Turco y suya, que me embiasse a mí, porque queria hablarme. [f.67 $\mathrm{v}^{\mathrm{o}}$ ] y toda la gente de Palacio con mucha rabia le preguntava adonde estava yo. Y assí el Embaxador se bolvió a casa muy turbado y atemorizado de tenerme en ella, temiendo algún assalto, tanto que me fué forçoso estar algunos días debaxo de tierra; y después, de noche, me puse en una pequeña barca en traje de Turco, hasta que Dios me traxo a tierra de salvamiento.

V. Don Gerónymo, después de aver confessado, fue llevado a la cárcel mayor de la ciudad, donde le tuvieron cinco meses, y hallándole siempre cons tantíssimo en la Fe Christiana, le llevaron ante el tribunal del gran Turco, donde, preguntado si era fiel Turco o Christiano, començó como buen soldado de Christo a predicar la Fe Catholica contra la seta Mahometana, diziendo con mucha libertad sus errores a los Turcos, y con palavras que les infamava su seta. Y assí el Consejo mandó que le cortassen la cabeça (como gentilhombre de Palacio, porque él tenía título de Agha — y a los plebeyos los ahorcan o los echan en la mar) en la pública plaça de Athmaydan. Y llegado a la dicha plaça, siempre constantissimo predicava en lengua Turquesca la fe de Christo; y antes de cortarle la cabeça se llegó a él un Baxá diziéndole: "Morath, 
arrepiéntete de lo que has dicho, y di que estavas borracho, que te perdona. remos, y te pondremos en mayor estado del que tenías antes." Pero Don Gerónymo de Orrea, como valeroso, atento el engaño, bolviéndole el rostro escupió en la cara del Baxá, llamándole instrumento del demonio. Y con esto el verdugo executó el golpe, haziéndole saltar la cabeça; y este dichoso martyrio fué a 28 de Julio de 1616.

[f ${ }^{\circ} 68 \mathrm{r}^{\circ}$ ] V1. Aunque el Embaxador de Francia Monsieur le Baron de Sanzi, como tan buen Catolico, procuró cobrar su cuerpo, no se le quisieron dar, mas de noche le echaron a la mar. Este sucesso fué causa de mi partida de Cons' tantinopla; porque entonces se supo que yo hazía huyr de aquella ciudad a muchíssimos esclavos Christianos, y induzía renegados que se bolviessen a la santa Fe. Y también se publicó que yo era espía de su Magestad Católica.

\section{ANOTACIONES A UN PARÉNTESIS}

El pasaje más oscuro de toda nuestra novela es seguramente el de los "intercolunios" que se intercalan entre el dolor de Silvia cautiva y la alegría de su reconocimiento con Felisardo. En él exagera Lope, de manera algo burda, el procedimiento que consiste en dejarse llevar de las asociaciones de ideas, para aprovechar "cuanto se viene a la pluma". Mientras en la mayoría de los casos la asociación trae una sentencia más o menos pertinente para comentar una situa. ción o una anécdota para ilustrar una idea, aquí se divierte Lope en pasar de una idea a otra por analogías tan puramente externas que nos recuerdan aquellos juegos verbales en que las frases se eslabonan por la identidad fonética de la sílaba final de una con la inicial de la siguiente.

Si esta serie de disparates resulta clara a partir de la segunda mención de Bellido de Olfos, nos quedamos en ayunas ante la primera mitad que mezcla los conocidísimos y tradicionales romances del sitio de Zamora con cosas menudas de actualidad. ¿Quién será "el autor de las relaciones de los toros, quexoso de su fortuna adversa", que sirve de eslabón entre la idea de la prosa historial y poética y la idea de Zamora? Sin pretender acertar con la solución del enigma, creo posible relacionar la alusión de la novela con esta donosa anécdota de la Epístola al Doctor Matias de Porras, obra del mismo momento, incluida por Lope en el mismo tomo de La Circe (fo 181) :

Passó a las Indias con las manos puestas, por su favor un hombre de Zamora, para rogar y recibir dispuestas.

Éste por largo tiempo (que en un hora no se ganó Zamora) adquirir pudo treynta mil pesos, la Codicia autora.

Vino a su patria, y no por necio y rudo mas para parecer Filosofante, no quiso que ganasse un solo escudo.

Y dixo: "Si el descanso es importante, Yo me quiero comer este dinero, sin dar, sin emprestar, sin ser tratante;

no quiero censos, ni mohatras quiero, 
pues hijos no me heredan que me lleven

a ver las relaciones del Botero.

Mis años, cuando mucho, aunque los ceven

Baco en aromas y perdiz pintada,

durar quinze años cortesmente deven.

Treynta mil pesos, plata ya labrada,

justos les caben a dos mil por año,

con que queda la vida rematada".

Hízolo assí, gastando sin engaño

cada año dos mil pesos, y al postrero

olvidóse la muerte de su daño.

Pues como vió gastado su dinero, su vida a la limosna remitida, andava por las calles muy severo

diciendo en voz de todos entendida:

"Señores, den por Dios a un hombre honrado a quien faltó dinero, y sobró vida".

¿Quién será el hombre de Zamora? ¿Alguna figura de la bohemia literaria de la Corte? ¿Se dedicaría para remediar su penuria a escribir y vender relaciones de las fiestas de toros? Tal vez derrame alguna luz sobre el particular el tomo II de la suma taurina de José $M a$ de Cossío. En la Biblioteca Nacional de París, sólo he visto dos relaciones de las fiestas reales de Toros y cañas que se hicieron en la plaza de Madrid el lunes 21 de agosto de 1623 con motivo de los desposorios del Príncipe de Gales con la Infanta María de Austria. Son pliegos sueltos de gran tamaño, in folio (Relaciones curiosas, vol. II. Rés. Oa 198 bis, piezas núm. 4 y 3 ). La relación más extensa, que llena ocho páginas densas, impresas en Madrid por Juan González, es obra de un doctor Juan Antonio de la Peña, natural de Madrid, y va dedicada al Marqués de Villena, don Felipe Pacheco. La otra, mucho más breve, es un pliego de cuatro páginas: es anónima y no tiene pie de imprenta. ¿Tendrá algo que ver con ella el hombre de Zamora?

De todos modos, si es de Zamora el autor de unas relaciones taurinas conocidas por aquel entonces, se comprende que Lope, en son de burla, celebre el gran servicio que aquel desdichado hace a los zamoranos con merecer que el "novelador" mencione aquí la famosa ciudad, tan olvidada desde que pasaron de moda los romances del rey don Sancho. Y sumida la mente del escritor en ideas de literatura de cordel, salta a los romances de don Álvaro de Luna, cuya fama encarece diciendo que "casi llegaron a competir" con ellos los de la leyenda zamorana. Se trata evidentemente de los romances publicados en pliegos sueltos como los cuatro descritos por Durán (Romancero general vol. I, Bibl. Aut Esp., vol. X, pág. LxxxII), composiciones tardías con que un "poeta de asonantes" tomó a destajo el enriquecer el ciclo poético del Condestable. Estas cuatro "partes de los romances de don Álvaro de Luna" debieron de tener éxito, pues dice Lope que el autor, cuya faena fué interrumpida por la muerte antes de 1624, había "arrendado esta obligación por veinte años a los regidores de la fortuna". Es notable la mención de los mismos romances que aparece en La moza de Cántaro, comedia escrita o por lo menos retocada poco después de 1625 (cf. S. G. Morley and Bruerton, Chronology, op.cit, pág. 222). Viene para coronar una enumeración de las cosas variadísimas que vende el comercio 
callejero de la Corte, con sus mil oficios menudos ("modos de vivir que no dan de vivir" según dirá Fígaro) :

. . Cosas la corte sustenta
que no sé cómo es posible.
iQuién ve tantas diferencias
de personas y de oficios,
vendiendo cosas diversas!
Bolos, bolillos, bizcochos,
turrón, castañas, muñecas,
bocados de mermelada,
letüarios y conservas;
mil figurillas de azúcar,
flores, rosarios, rosetas,
rosquillas y mazapanes,
aguardiente, y de canela;
calendarios, relaciones,
pronósticos, obras nuevas,
y a don Álvaro de Luna,
mantenedor destas fiestas.

(Bibl.Aut.Esp., vol. xxıv, pág. 560b)

Valgan estas indicaciones como prueba de la complejidad del ingenio de Lope, tanto en una digresión de disparates gratuitos como en la intuición del conjunto de una historia novelesca.

MARCEL BATAILLON. 